\title{
3-D WAVE FIELD AROUND SUBMERGED BREAKWATER
}

\author{
Amir Sharif Ahmadian ${ }^{1}$ and Richard Simons ${ }^{1}$
}

\begin{abstract}
Methods for designing submerged breakwaters are still being developed, particularly in respect of the 3D nature of wave-breakwater interaction. Many of the available design tools are inefficient as they are not able to provide any information on the spatial distribution of the wave field around breakwaters, and cannot therefore guarantee reliability and accuracy for the engineer. There is thus a need for an engineering design tool with the ability to model spatial variation of wave height. This paper proposes a method based on machine learning algorithms for predicting the nearshore wave field behind a submerged breakwater that includes both 2D and 3D effects. The proposed numerical model has been validated by various scales of laboratory data. Comparisons reveal the ability of the proposed model to predict the wave field around submerged breakwater.
\end{abstract}

Keywords: Submerged Breakwaters; Wave field; 3D; Wave transmission; Artificial Neural Networks; Numerical modeling

\section{INTRODUCTION}

Constructing submerged breakwaters is increasingly preferred as a means to reduce erosion, trap natural sediments and restore beaches. This is because of their lower construction costs and significant influence on dissipation of incident wave energy. However, shoreline response to submerged breakwaters is particularly influenced by the wave field behind the structure driven by coastal processes, particularly wave overtopping and diffraction, which obviously includes both 2D and 3D effects.

The 2D aspects of wave transmission behind submerged breakwaters and specifically wave transmission coefficient $K_{t}$ have been studied extensively by researchers (Johnson et al. 1951; Adams and Sonu 1986; Losada et al. 1996; d'Angremond et al. 1996; Seabrook and Hall 1998; Schlurmann and Oumeraci 2002; Panizzo et al. 2003; Briganti et al. 2003; Wamsley and Ahrens 2003; van der Meer et al. 2005; Buccino and Calabrese 2007; Panizzo and Briganti 2007; Goda and Ahrens 2008). However, very few studies have focused on the 3D effects of submerged breakwaters (Bellotti 2004; Johnson et al. 2005; Zanuttigh and Martinelli 2008; Hur et al. 2012) and even fewer on the spatial variation of nearshore wave field behind this type of coastal structure (Kramer et al. 2005; Caceres et al. 2008; Vicinanza et al. 2009; Buccino et al. 2009).

Available 2D engineering design tools are inefficient in breakwater design as they are not able to provide any information on the spatial distribution of wave field around the breakwater. Also, the few recent studies of 3D effects on this kind of detached breakwater are mostly restricted to low-crested structures which are not fully submerged and therefore not applicable to fully submerged breakwaters. There is thus a need for a proper design tool to provide full information of spatial nearshore wave variation around submerged breakwaters. This fact encouraged authors to start the present study, intending to contribute to this major research topic and its future application not only to wave transmission modeling but also to driving forces required for coastal area flow circulation, sediment transport and morphodynamic modeling systems (Hanson and Kraus 1991).

The spatial distribution of the nearshore wave field around a submerged breakwater considering combined diffraction-overtopping is investigated numerically based on the data-driven algorithms known as Artificial Neural Networks (hereafter: ANNs). Computational prediction models of ANNs have proven to be useful in many fields of engineering to solve complicated nonlinear problems such as regression where many relations are involved. ANNs have previously been applied successfully in research related to coastal engineering (Mase et al. 1995; Van Gent and van den Boogaard 1998; Medina 1999; Medina et al. 2002; Kambekar and Deo 2003; Verhaeghe 2005; Panizzo and Briganti 2007; Verhaeghe et al. 2008). In this study, an ANN model has been designed and trained using experimental data collected from tests performed at different scales. The wave transmission coefficients calculated by the proposed model were compared with the measured experimental data. Comparison of calculated and measured wave data reveals the accuracy of the proposed model and its capability of predicting the wave field around submerged breakwaters. The agreement with experimental data is encouraging.

\footnotetext{
${ }^{1}$ Civil, Environmental and Geomatic Engineering Department, UCL, Gower Street, London, WC1E 6BT, UK
} 


\section{ARTIFICIAL NEURAL NETWORKS}

Artificial neural networks consist of a massive number of computational units positioned in ordered layers and linked together with network weights. A supervised feed-forward scheme known as a Multi-Layer Perceptrons (MLPs) network is employed in this study and will be discussed further below. However, for more information about this approach, please see: (Haykin 1998).

Basically, supervised feed-forward networks employ a mathematical method for the learning process (here, a back-propagation (BP) algorithm) to find a non-linear relationship between input data. Through the learning process network parameters such as interlayer weights and bias values are modified and adapted so as to minimize an overall error $E$ produced over all the patterns in the training set $s$ as follows:

$$
E=\sum_{i \in s} \frac{\left(t_{i}-y_{i}\right)^{2}}{2}
$$

where $t_{i}$ and $y_{i}$ and are respectively target response and computed output by the network for $i^{\text {th }}$ sample.

MLPs include an input layer, one or more hidden layers and an output layer of neurons. MLPs are usually trained by the BP algorithm in two phases (Rumelhart et al. 1986; Werbos 1988). First, the network's parameters are selected and the input signal is propagated through the layers. MLP networks apply transfer functions which compute the inner product of the network's weights and the input vectors. An overall error $E$ is computed at the end by comparing the network's response with the desired output. Then, in the second phase, the calculated error $E$ is propagated backward through the network. The network's parameters are adjusted so as to minimize the overall error $E$ and training is completed.

\section{EXPERIMENTAL SETUP AND DATA SAMPLING}

This section describes the experimental setup, equipment, data sampling and test conditions. The tests were carried out in a $20 \mathrm{mx} 1.2 \mathrm{mx} 1 \mathrm{~m}$ wave flume. The side walls of the flume were constructed with glass to provide clear visualization panels to monitor wave transformation around the breakwater during the tests. The horizontal bottom of the flume was made of glass with a $1 \mathrm{~V}: 15 \mathrm{H}$ sloping artificial stainless steel beach at the end for wave absorption. The length of the beach was $5.5 \mathrm{~m}$. The effectiveness of the wave absorption by the beach was investigated for all test conditions in the flume without any breakwater. A single absorbing piston type wave-maker was used to generate monochromatic waves in the flume. A round head breakwater with trapezoidal body sections was constructed and tested in the wave flume. The breakwater was constructed with horizontal top and side slopes of $1 \mathrm{~V}: 1 \mathrm{H}$ in all directions and made of smooth marine plywood. The breakwaters were fixed to the bottom of the flume so that the shoreward toe was located at a distance of $10 \mathrm{~m}$ onshore of the wave paddle. Offshore water depth was maintained at $300 \mathrm{~mm}$ for all experiments.

Measurements were made in different locations around the breakwater including front, side and behind. Wave height and water level changes along the flume and particularly behind the breakwater were measured by 21 wave gauges. The data sampling rate of water surface elevation using these wave gauges was set at 100 samples per second for each probe. The tests were conducted in the wave flume with different wave conditions and submergence depths. A total of 176 tests was performed under different combinations of 44 monochromatic wave climates including 11 wave heights and 4 wave periods with 4 different water depths. 35 tests were also carried out in the flume with the same water depth and similar wave conditions without the breakwater to examine the incident wave heights and beach reflections.

The range of test conditions (water depth, wave period and target wave heights) are presented in Table 1. All the tests were monitored with video cameras installed on the top and side of the flume and the observations recorded on tapes for further analysis. In this table, $H_{i}$ is the incident wave

height, $L_{o}$ offshore wave length, $h_{s}$ water depth over the breakwater crest, $h$ water depth in the toe of breakwater, $\theta$ and $r$ are polar coordinates. Fig. 1 shows a schematic plan and section of the submerged breakwater illustrating the physical parameters mentioned above. 


\begin{tabular}{|l|l|l|l|l|l|l|}
\hline \multicolumn{6}{|c|}{ Table 1. Range of parameters used to describe spatial wave transmission coefficient } \\
\hline Variable & $\begin{array}{l}H_{i} \\
(\mathrm{~mm})\end{array}$ & $\begin{array}{l}L_{o} \\
(\mathrm{~mm})\end{array}$ & $\begin{array}{l}h_{s} \\
(\mathrm{~mm})\end{array}$ & $\begin{array}{l}h \\
(\mathrm{~mm})\end{array}$ & $\begin{array}{l}\Theta \\
(\mathrm{rad})\end{array}$ & $\begin{array}{l}r \\
(\mathrm{~mm})\end{array}$ \\
\hline Mean & 51.33 & 1977.33 & 52.70 & 242.92 & 1.18 & 704.78 \\
\hline $\begin{array}{l}\text { Standard } \\
\text { deviation }\end{array}$ & 24.48 & 907.61 & 42.09 & 40.99 & 1.27 & 380.73 \\
\hline Maximum & 113.24 & 3379.67 & 112.50 & 300.00 & 3.10 & 1850.54 \\
\hline Minimum & 10.00 & 976.16 & 0.00 & 187.50 & -3.10 & 22.36 \\
\hline
\end{tabular}

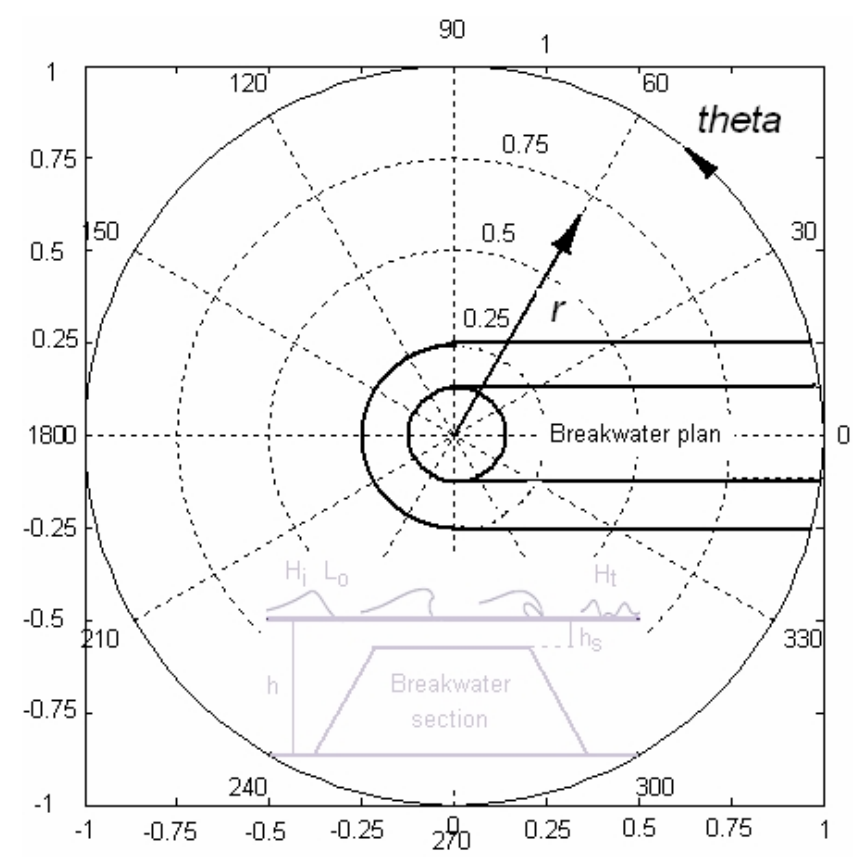

Figure 1. Parameters used for spatial wave transmission behind submerged breakwater

\section{EXPERIMENTAL DATA PROCESSING AND ANALYSIS}

An important aspect of experimental studies is the processing and analyzing of the data collected from the laboratory measurements to enhance its interpretation. Water surface elevation data, collected by wave probes along the wave flume, were used to calculate incident and reflected wave height, transmitted wave height behind breakwater and transmission coefficients. The method of Goda and Suzuki 1976 was implemented to calculate incident and reflected wave height. This method is basically a technique to decompose the incident and reflected wave heights by analyzing the amplitudes of Fourier components of recorded data from two wave probes located in front of the breakwater at an appropriate distance from each other and from any reflective surface. The wave transmitted onshore of the submerged breakwater varies spatially. This phenomenon was clearly observed throughout the laboratory tests. The average root mean squared wave height $\left(\hat{H}_{r m s}\right)$ from the probes behind the structure was calculated and used for analysis. Table 2 presents the range of non-dimensional data used in the neural network modeling, including minimum, maximum, mean and standard deviation of each individual parameter.

\begin{tabular}{|l|l|l|l|l|l|l|}
\hline \multicolumn{7}{|l|}{ Table 2. Non-dimensional input parameters employed in ANN model } \\
\hline $\begin{array}{l}\text { Nondimensional } \\
\text { parameters }\end{array}$ & $\frac{H_{i}}{L_{o}}$ & $\frac{h_{s}}{H_{i}}$ & $\frac{H_{i}}{h}$ & $\frac{h_{s}}{h}$ & $\theta$ & $\frac{r}{L_{o}}$ \\
\hline Mean & 0.03 & 1.43 & 0.22 & 0.19 & 1.18 & 0.44 \\
\hline $\begin{array}{l}\text { Standard } \\
\text { deviation }\end{array}$ & 0.02 & 1.68 & 0.12 & 0.14 & 1.27 & 0.32 \\
\hline Maximum & 0.08 & 11.25 & 0.60 & 0.37 & 3.10 & 1.90 \\
\hline Minimum & 0.01 & 0.00 & 0.03 & 0.00 & -3.10 & 0.01 \\
\hline
\end{tabular}


Therefore, $K_{t}$ will be determined as:

$$
K_{t}=f\left\{\frac{H_{i}}{L_{o}} \frac{h_{s}}{H_{i}}, \frac{H_{i}}{h}, \frac{h_{s}}{h}, \theta, \frac{r}{L_{o}}\right\}
$$

\section{ANN MODEL SETUP AND PERFORMANCE}

The MLP model in this research was designed with three layers of neurons including input, hidden and output layers as well as biases in the hidden and output layers. An optimum network should be selected during the model design. A cross-validation method (Haykin 1998) which proceeds as follows was employed for generalization. The entire collected laboratory data was divided into two main subsets for training and for testing. The set of training samples itself was split into two parts: estimation and validation subsets. The estimation subset contained data that were used to train the ANN model, while the validation subset was used to evaluate the model performance and monitor the training process. The network, tuned by the entire set of training data set, was finally verified against test data not used before. The philosophy behind employing test data is to test the trained neural network by data never used before, the network experiencing those inputs for the first time. This examines the performance and capability of the model under new conditions to ensure the model works properly and that generalization problems do not occur as new data are given to the model. The size of these three subsets is presented in Table 3.

\begin{tabular}{|l|l|l|l|}
\hline \multicolumn{4}{|l|}{ Table 3. Size of different data sets used for ANN model training and testing } \\
\hline \multirow{2}{*}{ Data sets } & Training & \multirow{2}{*}{ Testing (Set 3) } \\
\cline { 2 - 4 } & Estimation (Set 1) & Validation (Set 2) & \\
\hline Size & 3302 & 174 & 438 \\
\hline
\end{tabular}

To perform learning most effectively, the training samples were set to be completely random. Among different transfer functions, in MLP model, an antisymmetric hyperbolic tangent activation function was used for its better performance in BP learning in comparison with other functions such as the unsymmetrical logistic transfer function. To solve the scaling problem during the training, validation and testing as well as future application of the ANN model, a normalization process is essential. This goal might be achieved by Eq. 3:

$$
x_{n}=\frac{x-\min (x)}{\max (x)-\min (x)}
$$

where $\mathrm{x}$ is the value to be normalized.

Employing a BP algorithm increases the training time, although increasing the number of hidden layers may improve the generalization. Therefore, in this research, it is assumed that one hidden layer is sufficient to be able to approximate the underlying unknown function properly. For a more detailed description see (Hagan et al. 1996) or (Haykin 1998). Once the number of hidden layers of the network is determined, the number of hidden neurons in this layer should be determined. To achieve this, similar networks but with different numbers of hidden neurons were built and trained and the optimum number of hidden units then determined from the network which produced the least error in the validation subset. Fig. 2 presents the RMSE (Eq.1) error for 25 networks. As can be seen, both the estimation and validation error decreases during the initial phase of training. However, this reduction in computed error is offset to some extent, and with an increase in the hidden units, overlearning is introduced and consequently the error in the validation set begins to rise. In all cases, training was terminated once either the number of iterations reached its maximum limit or the computed response error was reduced to a value less than the target value. The network weights and biases were selected as the final model parameters at the point where minimum error in the validation subset was achieved. As can be seen in Fig. 2, the model with 7 nodes gives the least errors; hence 7 hidden neurons were chosen for the hidden layer of the model. 


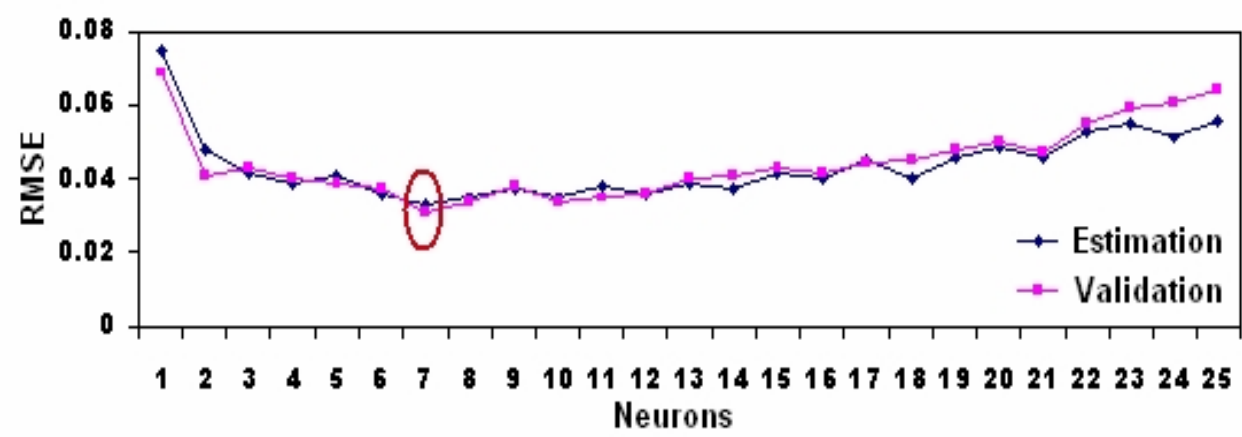

Figure 2. Root mean square error computed for the same ANN models but with different numbers of computational units in the hidden layer of the network

The predictions obtained from the MLP model are shown in Fig. 3, along with the corresponding observed data for two dimensional and non-dimensional cases. Two separate models have been designed, one based on the dimensional training data set (Table 1) and the other using non-dimensional training data (Table 2).
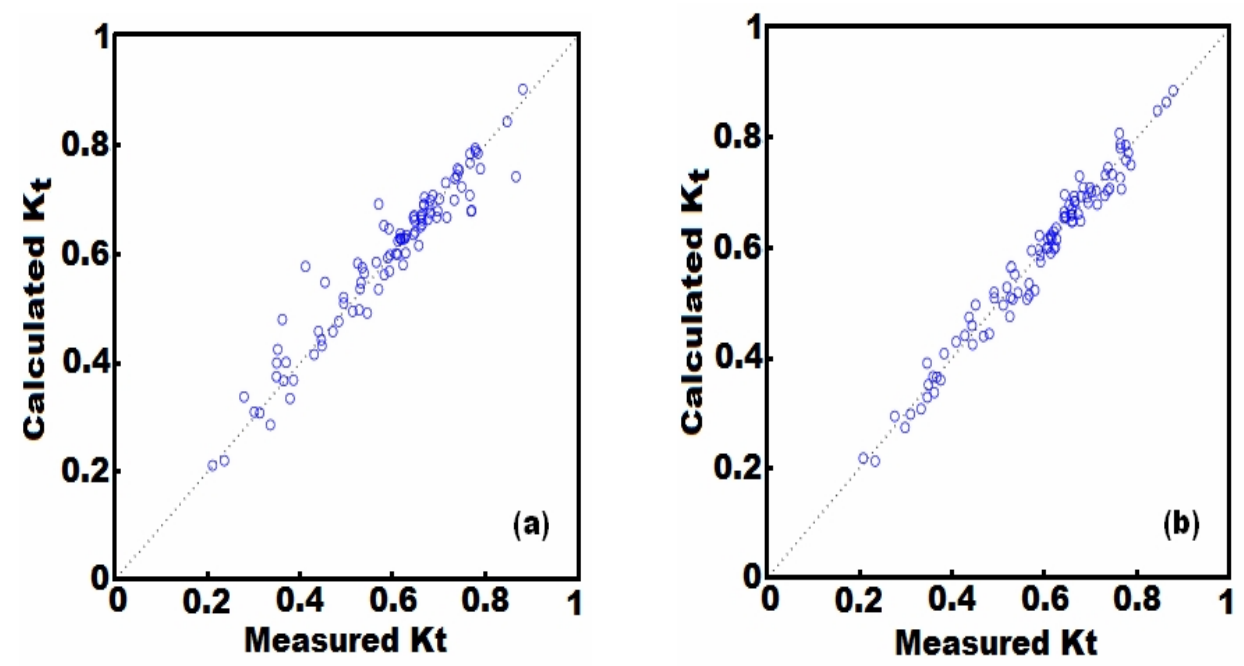

Figure 3. Scatter plot between predicted and measured transmission coefficient $K_{t}$ and comparison between two ANN models: (a). Model based on dimensional data set, (b) Model based on non-dimensional data set. Correlation coefficient $R^{2}$ is estimated using Equation 5.

Comparison of the two models against the experimental data was also made using two statistical parameters: Root Mean Squared Error (RMSE) and the squared multiple correlation coefficient $R^{2}$ :

$$
R M S E=\left[\frac{\sum_{i=1}^{N}\left(\frac{X_{c_{i}}-X_{m_{i}}}{X_{m_{i}}}\right)^{2}}{N}\right]^{1 / 2}
$$




$$
R^{2}=\frac{\left(\sum_{i=1}^{N}\left(X_{m_{i}}-\bar{X}_{m}\right)\left(X_{c_{i}}-\bar{X}_{c}\right)\right)}{\sum_{i=1}^{N}\left(X_{m_{i}}-\bar{X}_{m}\right)^{2} \sum_{i=1}^{N}\left(X_{c_{i}}-\bar{X}_{c}\right)^{2}}
$$

Table 4 shows the statistical comparisons of the two MLP models. The non-dimensional MLP model gives a better performance in predicting wave transmission coefficient compared with the dimensional model. This can be observed from the graphs and from the statistical indexes (i.e. lower RMS error and higher $R^{2}$ ).

\begin{tabular}{|l|l|l|}
\hline \multicolumn{3}{|l|}{ Table 4. Statistical comparison of two ANN models } \\
\hline Statistical indexes & RMSE & $R^{2}$ \\
\hline Dimensional model & 0.09 & 0.91 \\
\hline Non-dimensional model & 0.05 & 0.97 \\
\hline
\end{tabular}

Based on these comparisons, the non-dimensional neural network model was adopted and used to predict wave transmission coefficients around the submerged breakwater. Validation of the model against testing data set and its overall performance will be assessed in detail in the following sections.

\section{MODEL VERIFICATION}

\section{Accuracy Analysis}

The proposed ANN model in this paper has been validated using experimental data measured in the wave flume which were not used during the training process. The comparison of the proposed model with the experimental data was made by comparing five statistical parameters, including the Root Mean Square Error (RMSE ) and the squared multiple correlation coefficient $R^{2}$ as defined in previous section together with three additional parameters: Wilmott index $I_{w}$ (Wilmott, 1981), bias or distortion $\beta$, and error function $\varepsilon$ (Haller et al., 2002):

$$
\begin{aligned}
& I_{w}=1-\frac{\sum_{i=1}^{N}\left(X_{c_{i}}-\bar{X}_{m_{i}}\right)^{2}}{\sum_{i=1}^{N}\left(\left|X_{c_{i}}-\bar{X}_{m}\right|+\left|X_{m_{i}}-\bar{X}_{m}\right|\right)^{2}} \\
& \beta=\frac{\sum_{i=1}^{N}\left(\frac{X_{c_{i}}}{X_{m_{i}}}\right)}{N} \\
& \varepsilon=\left[\frac{\sum_{i=1}^{N}\left(X_{c_{i}}-\bar{X}_{m_{i}}\right)^{2}}{\sum_{i=1}^{N} X_{m_{i}}{ }^{2}}\right]^{1 / 2}
\end{aligned}
$$

where $N$ represents the number of data and where $X_{c}$ are the calculated values, $X_{m}$ are the measured values and the barred parameters demonstrate the average values of the parameters. Perfect agreement is achieved if $R^{2}$ and Wilmott index are 1.0 and the error function is zero; also, the values 
of distortion close to 1.0 and the lower values of RMSE show better agreement in the results. $R^{2}$ is considered unsatisfactory as a measure of the goodness of fit for a multivariate regression relationship (Draper, 1984) and thus the validity of the model will be assessed mostly by the other parameters.

The values of the five statistical parameters are presented in Table 5. The values of the statistical indicators indicate that the ANN model is able to determine wave transmission coefficient with very high accuracy. The values calculated using the ANN provide high $R^{2}(95 \%)$ and Wilmot number $I_{w}$ (75\%) and low values of $\varepsilon(0.24)$ and RMSE $(0.07)$ as well as value of distortion very close to 1.0 , indicating very good accuracy of results.

\begin{tabular}{|c|c|c|c|c|c|}
\hline Statistical index & $I_{w}$ & $R^{2}$ & $\beta$ & RMSE & $\varepsilon$ \\
\hline $\begin{array}{l}\text { Non-dimensional } \\
\text { ANN model }\end{array}$ & 0.75 & 0.95 & 0.99 & 0.07 & 0.24 \\
\hline
\end{tabular}

Investigation of the model performance also has been made graphically. Fig. 4 shows the correlation between values predicted by the ANN model and values measured in the flume for the test subset.

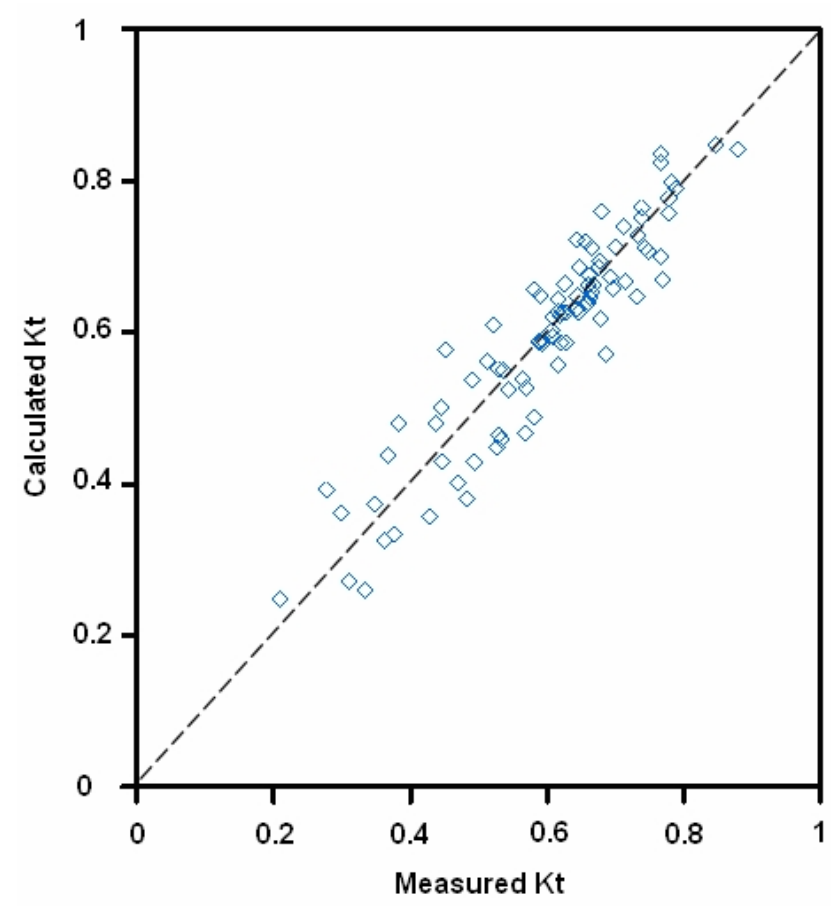

Figure 4. Measured vs. predicted values of the wave transmission coefficient $K_{t}$ (Set $3 ; h_{s}=60 \mathrm{~mm}, h=$ $250 \mathrm{~mm}, r=500 \mathrm{~mm}, \theta=1.05 \mathrm{rad}$ )

Fig. 5 shows a contour map of the error in the wave transmission calculated by ANN, giving a graphical illustration of the differences between calculated and measured wave heights in different regions around the submerged breakwater. This graph illustrates clearly the error at different points, thus providing valuable spatial information about the performance of the ANN model. As can been seen in this graph, the ANN model performs very well with very low error (mostly less than \%5) in most regions including that behind the breakwater and around the head. Higher values in error, between $5 \%$ and $10 \%$, can be seen in some small areas. 


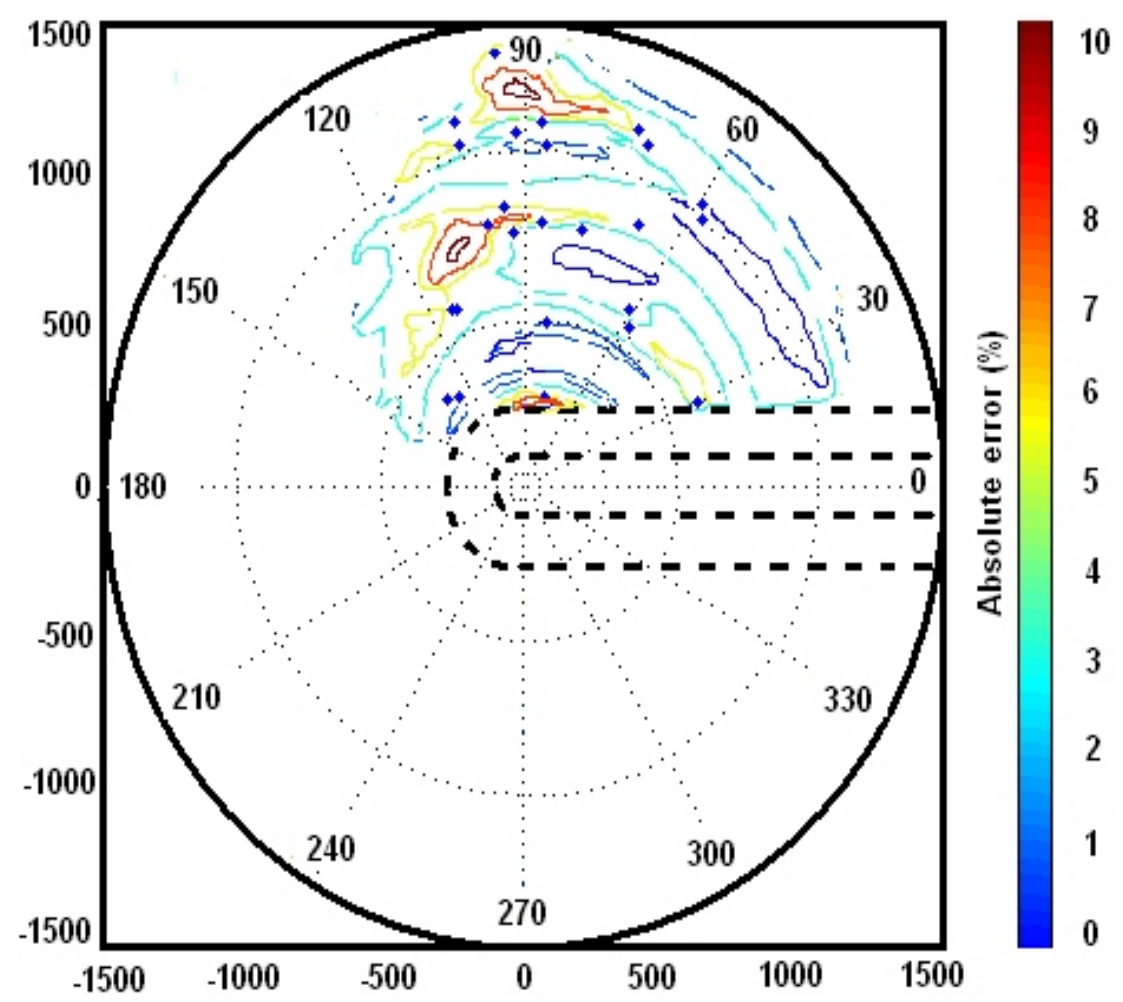

Figure 5. Contour map of computed absolute error of predicted compared with measured values (Set 3; $H_{i}=$

$68 \mathrm{~mm}, T=1 \mathrm{sec}, h_{s}=60 \mathrm{~mm}, h=250 \mathrm{~mm}$ )

All these evaluations reveal reasonable consistency between the measured data and results from the proposed model in the case of wave transmission coefficient prediction. It is evident that the trained non-dimensional ANN model is powerful enough to predict wave transmission coefficients spatially behind the submerged breakwater for a wide range of water depths and wave climates.

\begin{tabular}{|l|l|l|l|l|l|l|}
\hline \multicolumn{6}{|c|}{ Table 5. Sensitivity analysis of the Non-dimensional ANN model } \\
\hline $\begin{array}{l}\text { Omitted } \\
\text { parameters }\end{array}$ & $\frac{H_{i}}{L_{o}}$ & $\frac{h_{s}}{H_{i}}$ & $\frac{H_{i}}{h}$ & $\frac{h_{s}}{h}$ & $\theta$ & $\frac{r}{L_{o}}$ \\
\hline$R^{2}$ & 0.77 & 0.90 & 0.87 & 0.85 & 0.50 & 0.76 \\
\hline RMSE & 0.14 & 0.10 & 0.11 & 0.11 & 0.21 & 0.18 \\
\hline
\end{tabular}

\section{CONCLUSIONS}

Comparisons reveal the accurate performance and reliable predictions of ANN models. The following conclusions can be drawn: the performance of the ANN model with non-dimensional parameters was better than the one with dimensional parameters in the prediction of wave transmission coefficient around a submerged breakwater. Accuracy analysis illustrates very good results from the ANN-MLP model for spatial prediction of $K_{t}$ over a wide range of water depths and wave conditions. Sensitivity analysis showed that the non-dimensional parameter $\theta$ was the most effective parameter among all the effective parameters involved in the process. The parameters $H_{i} / L_{o}$ and $r / L_{o}$ also have a considerable influence on the results. Without these parameters as inputs to the network in the test data, the minimum correlation coefficient and the most error was obtained. All these evaluations reveal consistency between the measured data and results from the proposed model. It is evident that the trained ANN model is powerful enough to predict wave transmission coefficients. 


\section{REFERENCES}

Adams, C.B. and C.J. Sonu, 1986. Wave Transmission Across Submerged Near-Surface Breakwaters. In ASCE, pp. 1729-1738.

Bellotti, G., 2004. A simplified model of rip currents systems around discontinuous submerged barriers. Coastal Engineering, 51 (4), pp.323-335.

Briganti R, J.W. Van der Meer, M. Buccino, M. Calabrese, 2003. Wave transmission behind low crested structures. Proc 3rd Coastal Structures Conference.

Buccino M., D.I. Vicinanza, C.M. Caceres, 2009. 3D wave field behind impermeable low crested structures. Journal of Coastal Research, 56, pp.477-481.

Buccino, M and M. Calabrese, 2007. Conceptual approach for prediction of wave transmission at lowcrested breakwaters. Journal of Waterway, Port, Coastal and Ocean Engineering, 133(3), pp.213224.

Caceres I., M.J.F. Stive, A. Sanchez-Arcilla, L.H. Trung, 2008., Quantifcation of changes in current intensities induced by wave overtopping around low crested structures. Coastal Engineering, 55, p.113-124.

d'Angremond K., J.W. Van der Meer, R.J. De Jong, 1996. Wave transmission at low-crested structures. Proceedings of the 22th International Conference on Coastal Engineering Orlando, FL, USA, pp.2418-2426.

Goda Y., and J.P. Ahrens, 2008. New formulation of wave transmission over and through low-crested structures. Proceedings of the 31st International Conference of Coastal Engineering, 4.

Goda, Y. and Y. Suzuki, 1976. Estimation of incident and reflected waves in random wave experiments. In Proc. 15th Int. Conf. on Coastal Engineering, ASCE. pp. 828-845.

Hagan, M.T., H.B. Demuth, M.H. Beale, 1996. Neural network design, PWS Pub.

Hanson, H. and N.C. Kraus, 1991. Numerical Simulation of Shoreline Change at Lorain, Ohio. Journal of Waterway, Port, Coastal, and Ocean Engineering, 117(1), pp.1-18.

Haykin, S., 1998. Neural Networks: A Comprehensive Foundation by Simon Haykin (1998, Hardcover, Subsequent Edition): A Comprehensive Foundation, Prentice Hall.

Hur D.S., W.D. Lee. W.C. Cho, 2012. Three-dimensional flow characteristics around permeable submerged breakwaters with open inlet. Ocean Engineering, 44, pp.100-116.

Johnson, H.K., T.V. Karambas, I. Avgeris, B. Zanuttigh, , D. Gonzalez Marco, and I. Caceres, 2005. Modelling of waves and currents around submerged breakwaters. Journal of Coastal Engineering, 52, 949-969.

Johnson, J.W., R.A. Fuchs, and J.R. Morison, 1951. The damping action of submerged breakwaters. Transactions, American Geophysical Union, Vol. 32, No. 5, 704-718.

Kambekar A.R., and Deo M.C. 2003, Estimation of pile group scour using neural networks, Applied Ocean Research, Elsevier, Oxford, UK, 25(4) 225-234.

Kramer, M., B. Zanuttigh, J.W van der Meer, C. Vidal, , F.X. Gironella, 2005. Laboratory experiments on low-crested breakwaters. Coastal Engineering. 52, 867-885.

Losada, I.J., R. Silva, M.A. Losada, 1996. 3-D non-breaking regular wave interaction with submerged breakwaters. Coastal Engineering, 28, pp.229-248.

Mase, H., M. Sakamoto, T. Sakai, 1995. Neural Network for Stability Analysis of Rubble-Mound Breakwaters. Journal of Waterway, Port, Coastal, and Ocean Engineering, 121(6), pp.294-299.

Medina, J.R., J.A., GonzÃlez-Escriv ̃̃, J.M.Garrido, J. De Rouck, 2002. Overtopping analysis using neural networks. Proceedings of the 28th International Conference on Coastal Engineering, ASCE, pp. 2165-2177.

Medina, J.R., 1999. Neural network modelling of runup and overtopping. ASCE Proc Coastal Structures Santander, 1, p.421-429.

Panizzo, A, R. Briganti, 2007. Analysis of wave transmission behind low-crested breakwaters using neural networks. Coastal Engineering, 54(9), pp.643-656.

Panizzo, A., R. Briganti, , J.W. Van der Meer, L. Franco, 2003. Analysis of wave transmission behind low crested structures using neural networks, Proc. 4th Int. Coastal Structures Conference, Portland, Oregon.

Rumelhart, D.E., G.E. Hinton, R.J. Williams, 1986. Learning representations by back-propagating errors., 323(6088), pp.533-536.

Schlurmann, T., M. Bleck, and H. Oumeraci, 2002. Wave transformation at artificial reefs described by the Hilbert-Huang transformation. Proceedings of the 28th International Conference on Coastal Engineering, 2, pp.1791-1803. 
Seabrook, S.R., K.R. Hall, 1998. Wave transmission at submerged rubblemound breakwaters. Proceedings of the Coastal Engineering Conference, 2, pp.2000-2013.

van der Meer, J.W., R. Briganti, , B. Zanuttigh, and B. Wang, 2005. Wave transmission at low-crested structures, including oblique wave attack. Journal of Coastal Engineering, 52, 915-929.

van Gent, M.R.A., H.F.P. van den Boogaard, 1998. Neural network modelling of forces on vertical structures. Proceedings of the International Conference on Coastal Engineering, 1(26). pp.20962109.

Verhaeghe, H., J.D. Rouck and J. van der Meer, 2008, Combined classifier-quantifier model: A 2phases neural model for prediction of wave overtopping at coastal structures, Coastal Engineering, Elsevier, 55 (2008) 357-374.

Verhaeghe, H., 2005. Neural network prediction of wave overtopping at coastal structures. Ph.D. Thesis, Universiteit Gent, Gent, Belgium, ISBN 90-8578-018-7.

Vicinanza D., I. Caceres, M. Buccino, X. Gironella. and M. Calabrese, 2009. Wave disturbance behind low-crested structures: Diffraction and overtopping effects. Coastal Engineering, 56, pp.11731185.

Wamsley, T.V., J.P. Ahrens, 2003. Computation of Wave Transmission Coefficients at Detached Breakwaters for Shoreline Response Modeling. ASCE Conference Proceedings, 147(40733), p.49.

Werbos, P.J., 1988. Backpropagation: past and future. In Neural Networks, 1988., IEEE International Conference on. vol.1 pp. 343-353.

Zanuttigh, B., L. Martinelli, 2008. Transmission of wave energy at permeable low crested structures. Coastal Engineering, 55(12), pp.1135-1147. 